\title{
BMJ Open Measuring the impact of a social programme on healthcare: a 10 -year retrospective cohort study in Trieste, Italy
}

\author{
Luigi Castriotta (D) , ${ }^{1}$ Manuela Giangreco, ${ }^{2}$ Maria Grazia Cogliati-Dezza, ${ }^{3}$ \\ Marco Spanò, ${ }^{3}$ Enrico Atrigna, ${ }^{3}$ Claudia Ehrenfreund, ${ }^{3}$ Valentina Rosolen, ${ }^{2}$ \\ Flavio Paoletti, ${ }^{3}$ Fabio Barbone ${ }^{4}$
}

To cite: Castriotta $L$,

Giangreco M, Cogliati-Dezza MG et al. Measuring the impact of a social programme on healthcare: a 10-year retrospective cohort study in Trieste, Italy. BMJ Open 2020;10:e036857. doi:10.1136/ bmjopen-2020-036857

- Prepublication history for this paper is available online. To view these files, please visit the journal online (http://dx.doi. org/10.1136/bmjopen-2020036857).

Received 07 January 2020 Revised 18 May 2020 Accepted 09 June 2020

\section{Check for updates}

\section{Author(s) (or their} employer(s)) 2020. Re-use permitted under CC BY-NC. No commercial re-use. See rights and permissions. Published by BMJ.

${ }^{1}$ Istituto di Igiene ed Epidemiologia Clinica, Azienda Sanitaria Universitaria Friuli Centrale, Udine, Italy

${ }^{2}$ Institute for Maternal and Child Health - IRCCS "Burlo Garofolo" - Trieste, Trieste, Italy

${ }^{3}$ Azienda Sanitaria Universitaria Giuliano Isontina, Trieste, Italy

${ }^{4}$ Department Medical Area -

DAME, Università degli Studi di Udine, Udine, Italy

\section{Correspondence to}

Dr Luigi Castriotta;

luigi.castriotta@asufc.sanita. fvg.it

\section{ABSTRACT}

Objectives Poor social conditions are strong determinants of poor health but positive health and healthcare changes caused by social interventions are difficult to demonstrate. In 2006, in Trieste (Italy), a social intervention known as 'Habitat Microaree' (HM) project was implemented in eight deprived neighbourhoods. In 2016, an observational study was launched to assess the impact of the HM project on healthcare.

Design Retrospective cohort study.

Setting The eight geographically defined neighbourhoods of Trieste involved in the $2006 \mathrm{HM}$ project, accounting for a total of 11380 residents.

Participants Participants were all residents in the intervention areas. By means of a propensity score based on deprivation index, age, sex, Charlson index and drug utilisation, a non-participating, comparison group was defined.

Intervention The community-based intervention consisted of facilitating access to social services and outpatient healthcare facilities, coordinating intersectoral public services and specifically planning hospital discharge. These services were not provided in other areas of the city.

Outcome measures Hospital admissions and emergency department access.

Results We followed 16256 subjects between 2008 and 2015. Living in microareas was associated with an HR for first hospital admission, for all causes, of 0.95 (95\% $\mathrm{Cl} 0.91$ to 0.99 ); while the HR for urgent admissions in females was $0.92(95 \% \mathrm{Cl} 0.85$ to 1.00$)$. The HR for psychiatric disorders, in females, was $0.39(95 \% \mathrm{Cl} 0.18$ to 0.82$)$; in particular, the HR for psychosis was 0.15 (95\% $\mathrm{Cl} 0.05$ to 0.51 ). The $\mathrm{HR}$ for acute respiratory diseases in females was 0.44 (95\% Cl 0.21 to 0.95). In males, the HR for genitourinary diseases and heart diseases were 0.65 (95\% Cl 0.42 to 1.01 ) and 0.72 (95\% $\mathrm{Cl} 0.54$ to 0.97$)$, respectively. Concerning urgent multiple admissions, the OR for fractures in females was $0.75(95 \% \mathrm{Cl} 0.58$ to 0.97).

Conclusion In the study period, the effects on healthcare appear evident, especially in females.

\section{INTRODUCTION}

Material deprivation is an outcome-based measure of material well-being and material
Strengths and limitations of this study

- This study involved a large cohort for a long followperiod and the use of administrative databases as a data source, provided a complete picture of the subjects' access to healthcare facilities, diagnoses, therapies and treatments in the study period.

- To our knowledge, this is one of few studies that evaluate the effectiveness of a social intervention in terms of impact on health service.

- Our data derive from the administrative databases through an anonymous identifier, therefore, although not all residents were directly involved in the Habitat Microaree (HM) project, in our analysis all residents in the selected microareas were considered as participants in the HM project.

- Between 2009 and 2012, the HM project was extended to a further three microareas. Therefore, a number of residents, initially considered as nonparticipants, were subsequently involved in the intervention.

- Our results suggest that the HM project was more effective among females. This represents a limitation to the generalisability of the results.

deprivation rate is an indicator in the European Union statistics on income, and living conditions, adopted by the Social Protection Committee and used by the European Commission to set targets for the Member States. ${ }^{2}$ Townsend considered the material deprivation as the inability of living a decent life'. ${ }^{3}$ He stated 'People can be said to be deprived if they lack the types of diet, clothing, housing, environmental, educational, working and social conditions, activities and facilities which are customary, or at least widely encouraged or approved, in the societies to which they belong. They fall below standards of living which either can be shown to be widespread in fact or are socially accepted or institutionalised'. ${ }^{4}$ Sen agreed with Townsend on the concepts of 'shame' and 'inability to live a decent life 
with dignity' to explain the concept of material deprivation. ${ }^{5}$ To date, authors converge towards a definition of material deprivation as 'exclusion from the minimum acceptable way of life in one's own society because of inadequate resources, ${ }^{6-11}$ or 'the lack of socially perceived necessities'. ${ }^{12}$ Indeed, there is mounting evidence of an association between material deprivation and poor health conditions, in particularly with regard to chronic diseases whose risk increases over the life course. ${ }^{13}$ A Spanish nationwide small area study aimed to investigate the excess of mortality by first 10 leading causes associated to deprivation indexes, found that the higher the deprivation levels the higher the mortality risks, although this relation varied by gender and region. According to the authors, these findings support the idea that material deprivation causes health inequality through two mechanisms: by increasing the general susceptibility to diseases that lead to an excess of mortality for a wide range of causes; and through a set of more specific factors that lead to an excess of mortality for gender-specific causes. ${ }^{14} 15$

Furthermore, it has been shown that there is an increasing trend in annual access to emergency and urgent care in developed countries. ${ }^{16}$ Studies from the USA, Canada, the UK and Australia consistently reported demand for emergency department (ED) care increased from $3 \%$ to $6 \%$ per year. Between 1996 and 2006, in the USA, accesses to ED rose from $34.1 \%$ to $40.5 \%$ while in UK demand has more than doubled from 6.8 million ED accesses in 1966 to 14.3 million in 2012. ${ }^{17-20}$ However, according to the available studies, this phenomenon is attributable mainly to people with primary care problems who make improper use of emergency and urgent care services to access care. Relevant proportions of patients, ranging from $10 \%$ to $60 \%$, could be managed using services with lower and more appropriate care, and more accessible primary care could reduce unplanned secondary care use. ${ }^{1621}$ Material deprivation is one of the factors that affect the way health services are used; in a population-based cohort study, Brokamp et $a l^{22}$ found that a $10 \%$ increase in deprivation level caused a 1.03-fold increase (95\% CI 1.03 to 1.04) in length of hospital stay and a 1.02-fold increase (95\% CI 1.01 to 1.04 ) in risk of hospital utilisation. Raphael ${ }^{23}$ gave the definition of social determinants of health as 'economic and social conditions that shape the health of individuals, communities and jurisdictions as a whole'. Gender, education, income, housing, employment and access to healthcare shown an association with ill health.

Strong associations between social determinants and several health outcomes in different populations have been well documented as reported in Braveman and Gottlieb. ${ }^{24}$ Collaboration between public health workers and clinicians, developing health-promotion strategies, can improve the health outcomes for socially disadvantaged populations and can add more understanding of the mechanisms by which social determinants influence health. ${ }^{2526}$
Despite the compelling evidence on the social determinant of health, very few large community interventions have been conducted worldwide. The landmark health initiatives conducted in Trieste over the past 50 years, afford a comprehensive approach to these issues, along with mental and paediatric health. ${ }^{27-29}$ Trieste lies at the extreme northeast of Italy, close to the borders with Austria and Slovenia. The area is mostly urban (inhabitants: 234,493; area: $212 \mathrm{~km}^{2}$; density: 1,107/ $\mathrm{km}^{2}$; foreign nationality: $10 \%$ in 2019). ${ }^{30}$

In the last census conducted in Italy by the National Institute of Statistics in 2011, 27.6\% of people residing in Trieste were over 65 years of age (vs $20.5 \%$ in Italy) and life expectancy at birth was 79 years for males and 83.6 years for females (vs 79.5 for males and 84.4 for females in Italy). In Trieste, the mortality rate for all causes was 14.5 per 1000 inhabitants (vs 10.0 per 1000 inhabitants in Italy) and the birth rate was 7.3 per 1000 inhabitants (vs 9.2 per 1000 inhabitants in Italy). Fifty per cent of the population was not in the labour force (vs 49.2 in Italy) and $4.7 \%$ were looking for a job (vs $5.8 \%$ in Italy); $52.7 \%$ of residents in Trieste had a low education level (vs 58.7\% in Italy), $32.0 \%$ had a high school diploma (vs $30.2 \%$ in Italy) and $16.3 \%$ had a university degree or higher (vs $11.5 \%$ in Italy).$^{30}$

The city has been, and still is, rich in contrasts and owes much of its centuries-old tradition of multilingualism and multiculturalism to its role as a port which, however, has also brought inequalities in the physical and social milieu and in health. In particular, at the beginning of the new millennium, an increase in population ageing, a prevalence of chronic conditions and polypharmacy, and inequalities in the distribution of risk factors and welfare reliance, including public housing, resulted in uncontrolled access to care explainable more in terms of social determinants and uncoordinated provision of medical care than of acute clinical progression demand. In particular, in Trieste, there are well-defined neighbourhoods known as 'Microaree', with 500 up to 2500 inhabitants, characterised by a high prevalence of social housing, economic and social hardship and poor environment quality.

To improve the health status and the social capital of these deprived communities, in 2006, the local health authorities, in conjunction with the voluntary and public social housing sectors and private citizens, implemented a proactive joint intervention programme called 'Habitat Microaree' (HM). The HM project started on 1 January 2006 in eight 'Microaree' and was designed to act both at the individual level, ensuring proper access to health facilities and social services, as well as improving the coordination of services; and at the community level, supporting hospital discharges. The HM project was conceived as a joint intervention delivered in people's life setting and designed to act on multiple levels, health, social and housing, through a paradigm shift: services no longer as a set of a priori defined activities, but coproduced with people in order to engage them. ${ }^{31}$ 
In 2016, the University of Udine set up a retrospective cohort study to evaluate the effectiveness of this community-based social intervention, in terms of reduction of urgent admissions to both hospital and the ED, comparing subjects who lived in the microarea with subjects who lived in the neighbouring non-microarea quarters of Trieste. In conjunction and in coordination with this study, the University of Turin worked on the analysis of the social capital generated by the intervention in relation to the health status. Here, we present the results of the retrospective cohort study.

\section{METHODS}

The HM project started on 1 January 2006 in eight 'Microaree' of Trieste accounting for a total of 11380 residents. Eight multiprofessional teams were set up, one for each microarea, consisting of experts in continuum of care from the local health district, social workers from the municipality of Trieste and agents from the social housing agency. ${ }^{31}$ The HM activities to support the health and rights of citizens were linked to four intervention areas: (A) assessment of the priority health problems of the people residing in each microarea; (B) optimisation of interventions in support of home healthcare to prevent institutionalisation and improper hospitalisation; (C) promotion of collaboration between different institutions providing services to the same individual and on the same territory, through the active participation of the inhabitants and (D) fostering an active and participatory community. The close interrelationship and interdependence between socioeconomic factors, individual behaviours, the context of life and health make the reality of the Microaree extremely difficult to represent by classifying activities univocally in relation to specific objectives and areas of intervention. Table 1 shows some examples of the interventions delivered in the eight 'Microaree' of Trieste.

The study cohort and the associated variables of interest were extracted through record linkage with the administrative databases of the Regional Repository of MicroData of the Friuli Venezia Giulia region, using an anonymous identifier. The general population was made up by subjects who had lived in Trieste continuously in the 4years preceding 2006. Based on the address of each subject on 1 January 2006, the general population was categorised as: (1) 'resident in a microarea (M)' 2) 'non-resident in a microarea (NM)'. In order to make the two groups comparable, each M subject was matched with an NM subject through propensity score. ${ }^{32}{ }^{33}$ We used the Nearest Neighbour Matching method with a greedy algorithm without replacement. ${ }^{34-36}$ The matching variables were: sex, the 2001 deprivation index by Caranci, ${ }^{37}$ age on 1 January 2006, the Charlson index ${ }^{38}$ constructed using hospital admissions in the 4years preceding 1 January 2006, use of selected drugs in the year prior to 1 January 2006, identified according to the Anatomical Therapeutic Chemical classification system (ATC). ${ }^{39}$ The Caranci deprivation index is an estimate obtained by summing the standardised indicators of five traits, low level of education, unemployment, non-home ownership, one parent family and overcrowding that operationally combined represent the multidimensionality of the social and material concept of deprivation. ${ }^{37}$ The deprivation index by Caranci is available for each census block level in Italy. In our study, the categorised deprivation Caranci index was assigned based on the census block level of the subject's residence. The Charlson index predicts the mortality risk of a patient who has had one or more hospital admissions for a range of comorbid conditions in a defined time period. For each identified comorbid condition a score is assigned, that depends on the risk of dying from that condition. ${ }^{38}$ We considered hypertension drugs (ATC: 'C02', 'C03', 'C04', 'C07', 'C08'), diabetes drugs (ATC: 'A10A', 'A10B', 'A10X') and ulcer drugs (ATC: from 'A02BC01' to 'A02BC05', 'A02BA', 'A02AA', 'A02AB', 'A02AC', 'A02AD', 'A02AF', 'A02AG', 'A02AH', 'A02AX', 'A02X', from 'A02BD01' to 'A02BD07', 'A02BB', 'A02BX'). We matched five 'non-microarea' subjects to each 'microarea' subject by propensity score. Out of the five 'non microarea' subjects, we selected the one whose residence was closer to the residence of the matched 'microarea' subject.

At the end of the matching process we obtained a cohort in which we considered as 'participant' to HM programme the subjects who lived in a microarea continuously during the follow-up period (microarea participant, MP), and as 'non participant' to HM programme the subjects who lived in a non-microarea for any length of time during the follow-up period (non-microarea participant, NMP). In order to maximise the differences between the participants to HM and the non-participants to HM, we focused our analysis only on stable residents, thus excluding individuals who alternated periods living in a microarea with periods living in a non-microarea. Furthermore, we considered the first 2 years as latency time. The follow-up of the resulting cohort, therefore, lasted from 1 January 2008 to 31 December 2015.

The study outcomes were first admission to a regional hospital, first admission to a local ED, multiple admissions to a regional hospital and to a local ED, during the follow-up period. The first admission to a regional hospital was identified as the earliest hospital admission for all causes, for each International Classification of Diseases ninth edition (ICD9-CM) diagnosis class, and for each specific diagnosis (ICD9-CM defined), during the study period. The date of the admission was defined as the 'index date' and each comorbidity was identified. The first admission to the ED was defined as the earliest ED admission for all causes occurring during the follow-up period, with the date of admission as the 'index date'.

Admissions to regional hospitals were stratified in two groups: Ordinary (Planned+ Day hospital) and Urgent, while ED admissions were analysed according to triage priority codes: white (non-urgent conditions), green (minor injuries or illnesses), yellow (potentially life threating conditions) and red (life-threatening conditions). In the analysis, we also accounted for multiple hospital admissions and for multiple ED admissions. Multiple admissions were defined 
as repeated admissions of the same patient during the study period. We categorised multiple admissions in three classes: 0 admissions, 1 admission, $\geq 2$ admissions.

Participants and non-participants in the HM project intervention were compared in terms of first hospital admission and first access to ED, using Cox regression models. Person-time was calculated as difference between index date and beginning of follow-up. Multiple hospital admissions and ED accesses were analysed using ordered logistic regression models setting as reference the 0-category. All models were adjusted by age at the start of follow-up, by Charlson index and by the Caranci 2001 deprivation index and stratified by sex. The statistical software used for the analysis was the SAS software, V.9.4 (SAS Institute). This study was conducted in accordance with the 1964 Declaration of Helsinki and its later amendments.

\section{PATIENT AND PUBLIC INVOLVEMENT STATEMENT}

Anonymised patient data, from administrative databases, were used in this study; neither the patients nor the public were personally involved.

\section{RESULTS}

At enrolment, the MP subjects were 10,588, and a corresponding number of matched NMP subjects was identified. The stable residents at the beginning of the follow-up period were a total of 16256 (table 2).

The total follow-up time was 80325.19 years, with mean value equal to 4.90 years ( median $=5.5$ years; $Q 1=1.9$ years; $\mathrm{Q} 3=8$ years). The HR that compares MP and NMP for first hospital admission for all causes was $0.95(95 \% \mathrm{CI} 0.91$ to 0.99) while HRs for planned and urgent first admissions were, respectively, 0.97 (95\% CI 0.91 to 1.02 ) and 0.95 (95\% CI 0.90 to 1.01 ) (figure 1 ). Stratifying by gender, while in males, MP and NMP hazards for first admissions seemed to be broadly the same, in females the HR for first planned admission was 0.95 (95\% CI 0.88 to 1.02 ) and for urgent admission was 0.92 (95\% CI 0.85 to 1.00 ) (figure 2). When the analysis focused on the specific causes of hospitalisation, that is, by ICD9-CM diagnosis blocks, the HR of first urgent admission for mental disorders in females was 0.39 (95\% CI 0.18 to 0.82). An increased, although not statistically significant, HR for planned admissions for mental disorders was also observed (HR 1.51; 95\% CI 0.76 to 2.96) (figure 3). Again in females, the HR for first urgent hospitalisation caused by diseases of the genitourinary system was 0.74 (95\% CI 0.49 to 1.11 ), whereas for planned admissions the HR was 1.03 (95\% CI 0.82 to 1.31). Analysis of data on hospitalisation for diseases of the circulatory and respiratory systems showed a different pattern: HRs for circulatory system diseases were 1.15 (95\% CI 0.98 to 1.35 ) for urgent hospitalisation, and 0.91 (95\% CI 0.70 to 1.18 ) for planned admissions. HRs for respiratory system diseases were 0.95 (95\% CI 0.74 
Table 2 Microarea participant (MP) and non-microarea participant (NMP) stable residents

\begin{tabular}{lllll} 
& MP (N=6963) & & & NMP (N=9293) \\
\cline { 2 - 3 } & Females & Males & Females & Males \\
\hline $\mathrm{n}(\%)$ & $3793(54.5)$ & $3170(45.5)$ & $5020(54.0)$ & $54.5(22.3)$ \\
\hline Mean age (SD) & $57.7(19.7)$ & $53.6(19.8)$ & $50.3(20.6)$ \\
\hline
\end{tabular}

to 1.21 ) for urgent and 0.63 (95\% CI 0.42 to 0.94$)$ for planned hospitalisations, respectively.

In males, the most relevant results concerns hospitalisation for diseases of the genitourinary system, with HR for first urgent admissions equal to 0.65 (95\% CI 0.42 to 1.01), and for diseases of the circulatory system, with HR equal to 0.91 (95\% CI 0.77 to 1.08 ) for first urgent hospitalisation and 1.37 (95\% CI 1.08 to 1.74$)$ for planned admissions (figure 4).

Focusing on the specific diagnoses, some relevant results emerged: in females, the HR for first urgent admission for psychosis (n.27; ICD9-CM 290-299) was equal to 0.15 (95\% CI 0.05 to 0.51 ), while for acute respiratory infections (n.34; ICD9-CM 460-466) hour was 0.44 (95\% CI 0.21 to 0.95$)$. In males, the HR for first urgent admission for psychoses (n.21) was 0.49 (95\% CI 0.19 to 1.27 ), and for other forms of heart disease (n. 197; ICD9-CM 420-429) 0.72 (95\% CI 0.54 to 0.97 ). Regarding multiple admissions for all causes (table 3$)$, the OR was $0.93(95 \%$ CI 0.89 to 0.98$)$ in females and 0.98 (95\% CI 0.93 to 1.03 ) in males.

For urgent hospitalisations (table 4), the OR was 0.95 (95\% CI 0.90 to 1.00 ) in females and 1.03 (95\% CI 0.96 to 1.09 ) in males.

Of particular relevance was the OR for multiple urgent admissions for fractures (ICD9-CM 800-829) in females, equal to 0.75 (95\% CI 0.58 to 0.97$)$. Analysing hazards for first access to ED, a slight reduction emerged for white codes, both in females and in males; the HRs were, respectively, 0.97 (95\% CI 0.89 to 1.05 ) and 0.94 (95\% CI 0.86 to 1.03$)$. This reduction was found also for green codes but only in females: HR 0.94 (95\% CI 0.87 to 1.00$)$. For other priority codes, no risk differences emerged (data not shown). For what concerns multiple accesses to ED, again a minor reduction emerged for white codes both in

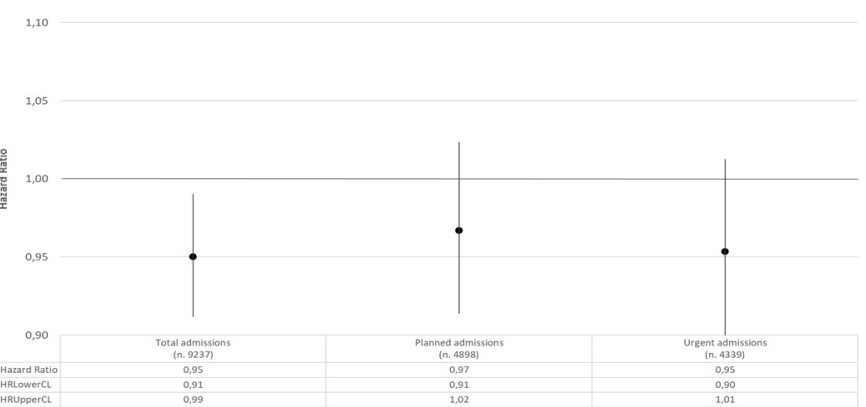

Figure 1 HRs for first hospital admission; MP versus NMP. Analysis adjusted for age and Charlson and deprivation indexes. MP, microarea participant; NMP, non-microarea participant. females and in males, with ORs, respectively, equal to 0.97 (95\% CI 0.91 to 1.02 ) and 0.97 (95\% CI 0.92 to 1.03$)$, and for green codes, but only in females, with OR equal to 0.95 (95\% CI 0.91 to 1.00$)$. No further significant results emerged for other priority codes (data not shown).

\section{DISCUSSION}

We focused on the hazards of first hospitalisation as main measurable outcomes, under the hypothesis that after the first hospital access patients are more likely to be involved in a controlled clinical follow-up, and therefore, subsequent hospital admissions may not be independent events. Our results show a slight reduction in hazard of first hospitalisation for all causes in MP. For urgent admissions in females, the reduction appears to be more pronounced. Similarly, hazards for first access to ED for the lowest priority access code, both in females and in males, seem to be slightly decreased. This reduction was found also for green codes but only in females, while for other priority codes, no risk differences emerged. In the literature, interventions such as patient education, needs assessment, telephone support and follow-up have been shown to effectively reduce hospital admissions. ${ }^{40} \mathrm{~A}$ meta-analysis by Panagioti et $a l^{41}$ showed that interventions aimed at improving self-management support, reduced health services utilisation, with no negative impact on patient health outcomes; in particular, robust evidence in this sense was found for respiratory and cardiovascular disorders. Coherently with these results, in our study, MP females, showed a lower risk for acute respiratory infections, while in MP males, a lower risk of first urgent hospitalisation for 'other forms of heart disease' was observed. However, the most remarkable finding that emerged from our study concerns psychosis, particularly in females. The longitudinal SMILE study in the Netherlands ${ }^{42}$ has shown that persons reporting material deprivation were at higher risk of physical and mental

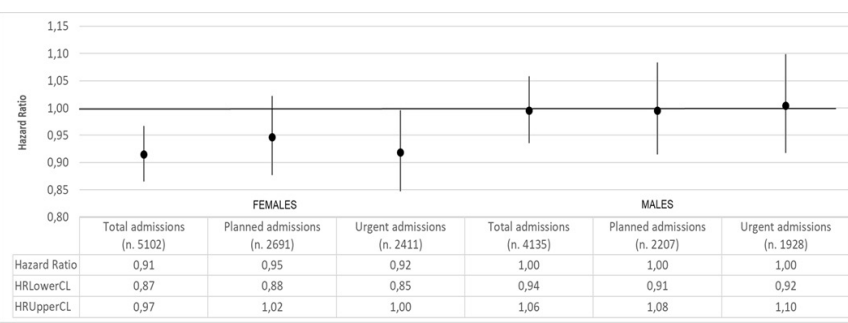

Figure 2 HRs for first hospital admission; MP versus NMP by gender. Analysis adjusted for age and Charlson and deprivation indexes. MP, microarea participant; NMP, nonmicroarea participant. 


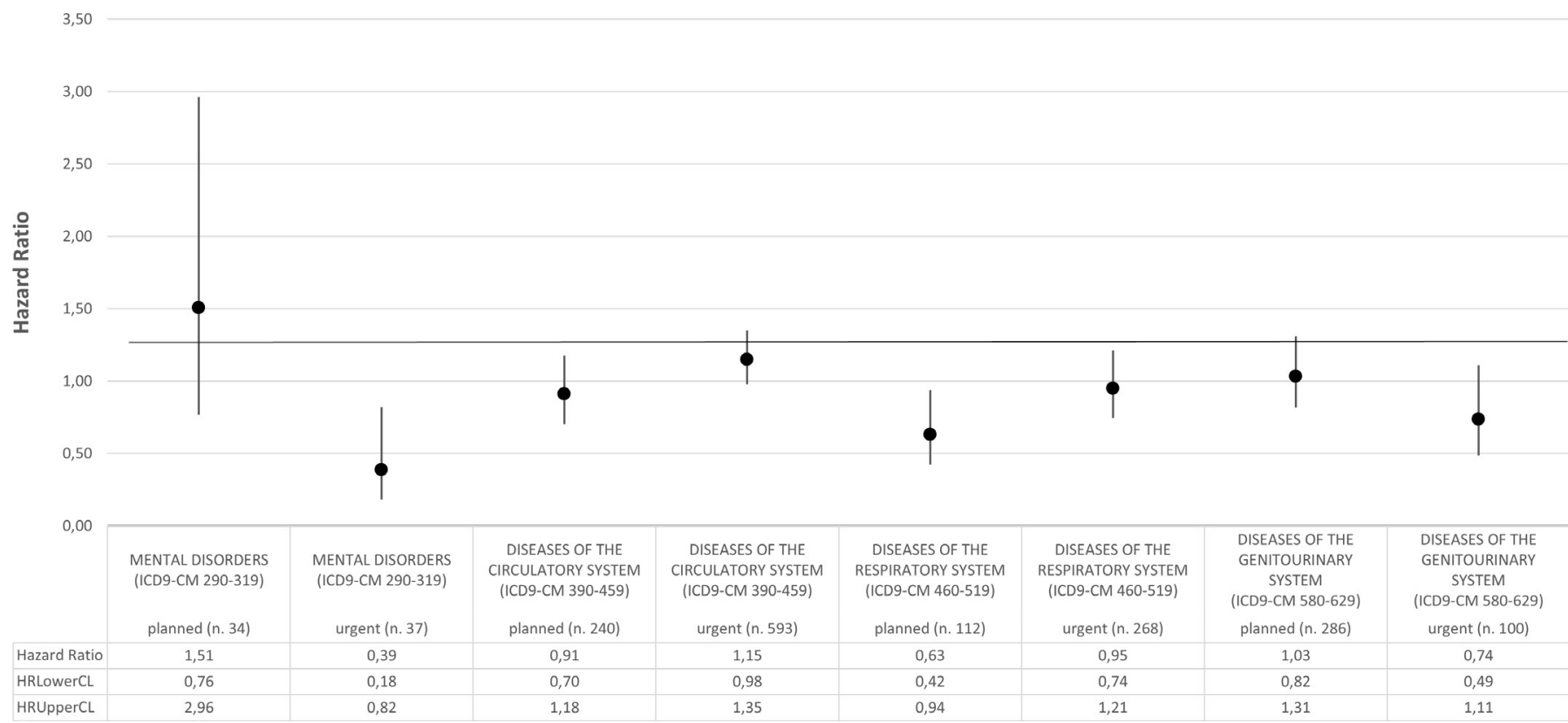

Figure 3 HRs for first hospital admission by ICD-9-CM blocks of diagnosis; MP versus NMP (females). Analysis adjusted for age and Charlson and deprivation indexes. ICD-9-CM, International Classification of Diseases ninth edition-Clinical Modification; MP, microarea participant; NMP, non-microarea participant.

disorders. In a meta-analysis of the effect of early interventions for psychosis, Randall et $a l^{43}$ describe a positive effect in terms of hospitalisation reduction. McFarlane $e t a l^{44}$ noted that admission rates for psychotic episodes were reduced by a community-wide programme of early identification and intervention initiated in 2001.

Multiple admissions represent a patient safety concern as well as a public cost. ${ }^{40}$ Socioeconomic status is strongly associated with hospital outcome measures and there is evidence showing that some multifaceted interventions can successfully reduce hospital readmissions. ${ }^{45}$ In a randomised control trial carried out between 1992 and 1996, Naylor et $a l^{46}$ studied the effectiveness of nurse-centred discharge planning and follow-up intervention for subjects at higher risk of readmission. Twenty-fourweeks after hospital discharge, readmission was more frequent for patients in the control group than in the intervention group.

Our results also suggest that the HM project was effective in reducing multiple admissions for all causes in females (table 3), and particularly for fractures.

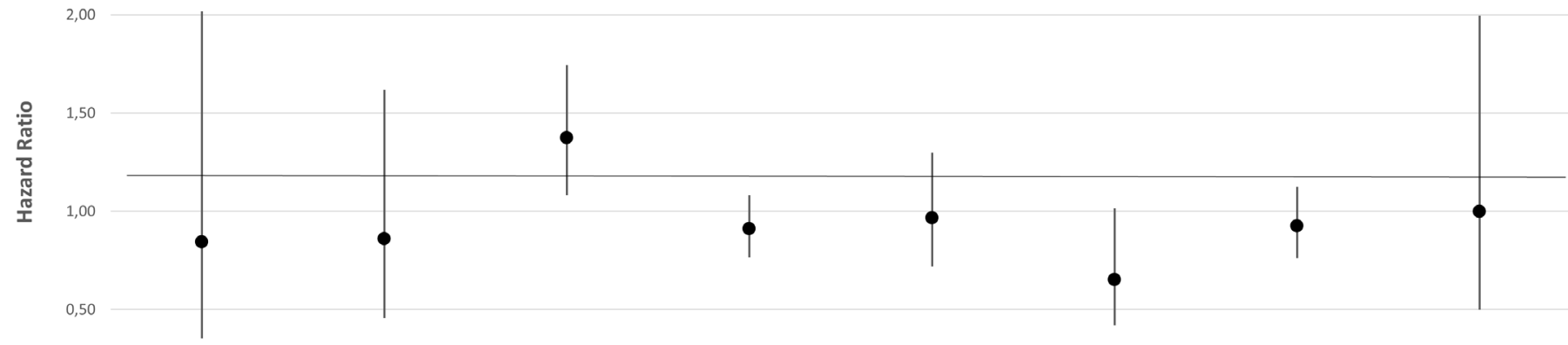

\begin{tabular}{|c|c|c|c|c|c|c|c|c|}
\hline & $\begin{array}{l}\text { MENTAL DISORDERS } \\
\text { (ICD9-CM 290-319) }\end{array}$ & $\begin{array}{l}\text { MENTAL DISORDERS } \\
\text { (ICD9-CM 290-319) }\end{array}$ & $\begin{array}{l}\text { DISEASES OF THE } \\
\text { CIRCULATORY SYSTEM } \\
\text { (ICD9-CM 390-459) }\end{array}$ & $\begin{array}{l}\text { DISEASES OF THE } \\
\text { CIRCULATORY SYSTEM } \\
\text { (ICD9-CM 390-459) }\end{array}$ & $\begin{array}{c}\text { DISEASES OF THE } \\
\text { GENITOURINARY } \\
\text { SYSTEM } \\
\text { (ICD9-CM 580-629) }\end{array}$ & $\begin{array}{c}\text { DISEASES OF THE } \\
\text { GENITOURINARY } \\
\text { SYSTEM } \\
\text { (ICD9-CM 580-629) }\end{array}$ & $\begin{array}{l}\text { DISEASES OF THE } \\
\text { MUSCULOSKELETAL } \\
\text { SYSTEM AND } \\
\text { CONNECTIVE TISSUE } \\
\text { (ICD9-CM 710-739) }\end{array}$ & $\begin{array}{l}\text { DISEASES OF THE } \\
\text { MUSCULOSKELETAL } \\
\text { SYSTEM AND } \\
\text { CONNECTIVE TISSUE } \\
\text { (ICD9-CM 710-739) }\end{array}$ \\
\hline Hazard Ratio & 0,84 & 0,86 & 1,37 & 0,91 & 0,97 & 0,65 & 0,93 & 1,00 \\
\hline HRLowerCL & 0,35 & 0,46 & 1,08 & 0,77 & 0,72 & 0,42 & 0,76 & 0,50 \\
\hline HRUpperCL & 2,02 & 1,62 & 1,74 & 1,08 & 1,30 & 1,01 & 1,12 & 2,00 \\
\hline
\end{tabular}

Figure 4 HRs for first hospital admission by ICD-9-CM blocks of diagnosis; MP versus NMP (males). Analysis adjusted for age and Charlson and deprivation indexes. ICD-9-CM, International Classification of Diseases ninth edition-Clinical Modification; MP, microarea participant; NMP, non-microarea participant. 
Table 3 Frequency distribution of all multiple hospital admissions (urgent + planned) by type of participant and gender

\begin{tabular}{lllll}
\hline $\begin{array}{l}\text { Multiple } \\
\text { admissions }\end{array}$ & Participant & Sex & Frequency & $\%$ \\
\hline 2 admissions & Microarea & F & 1318 & 23.9 \\
& & M & 1103 & 20.0 \\
& Not microarea & F & 1732 & 31.4 \\
& & M & 1357 & 24.6 \\
\hline
\end{tabular}

F, female; M, male.

For what concerns ED care services, there is evidence of an increased demand in countries where population ageing generates more diverse and complex care needs. ${ }^{47}$ Factors such as lack of access to affordable primary care around-the-clock and lack of awareness of available services or of diagnostic and therapeutic protocols, explain why the demand for these services is persistently increasing. In addition, patients of low socioeconomic status tend to prefer hospital care to primary care, because hospital care is perceived as higher quality and more convenient and accessible. ${ }^{48}$ Our results show that during the multifaceted HM project, the hazards of first access to ED for white codes slightly decreased, both in females and in males.

Our study presents some limitations: our data derive from administrative databases through an anonymous identifier, therefore, although in actual facts not all residents were directly involved in the HM project, for the purposes of our analysis, all residents in the selected microareas were considered as participants in the HM project. This may have introduced a certain degree of misclassification with a likely underestimation of the effectiveness of the intervention. Moreover, between 2009 and 2012, the HM project was extended to a further three microareas, therefore, among those whom we considered non-participants, there were residents who were in fact involved in the intervention. Again, this might have contributed to underestimate the effectiveness of the intervention. Our results suggest that the HM programme was more effective with females; based on the reports of the multiprofessional teams, a possible explanation may be that it was easier to involve females than

Table 4 Frequency distribution of multiple urgent hospital admissions by type of participant and gender

\begin{tabular}{lllll}
\hline $\begin{array}{l}\text { Multiple } \\
\text { admissions }\end{array}$ & Participant & Sex & Frequency & $\%$ \\
\hline 22 admissions & Microarea & F & 681 & 23.7 \\
& & M & 607 & 21.2 \\
& Not microarea & F & 886 & 30.9 \\
& & M & 695 & 24.2 \\
\hline
\end{tabular}

F, female; M, male. males. This, however, represents a limitation in terms of results generalisability.

Our study also presents a number of strengths: it involved a wide cohort for a long follow-period and the use of administrative databases provided a complete picture of the subjects' access to healthcare facilities, diagnoses, therapies and procedures during the study period. To our knowledge, this is one of few studies that evaluate the effectiveness of a social intervention in terms of impact on health services. In our view, this study may represent the starting point for a more comprehensive assessment aimed at determining the impact of the HM project on the healthcare system also in terms of costs, a topic of significant interest since sustainability of the public health service is a matter of great current concern.

\section{CONCLUSIONS}

Our results show that by acting on the social determinants of health, the burden on the health service can be controlled and reduced. Our evidence shows that during the follow-up period, there was a reduction of first urgent hospital admissions in the social intervention area, especially in females and for specific diagnoses such as psychosis. Also multiple admissions were decreased in the intervention group, again, mainly in females and for specific diagnoses such as fractures.

Acknowledgements The authors thank all the representatives of the 'Habitat Microaree' project for their valuable work.

Contributors LC, FB, MGC-D and FP conceived, designed and coordinated the study. MS, EA, CE and FP collected data. MG, LC and VR defined the statistical analysis plan and performed the analysis. LC, MG, FB, MGC-D and FP interpreted the results. LC and MG drafted the paper. FB, MGC-D, MS, EA, CE, FP and VR critically revised the manuscript.

Funding This retrospective cohort study was supported by a fund allocated by the local health authority of Trieste 'Azienda Sanitaria Universitaria Integrata di Trieste' on 31 August 2016 (CUP E97B16000340002) through an ad hoc agreement with the University of Udine. Researchers acted independently from the funder and all authors had full access to all data (including statistical reports and tables) in the study and can take responsibility for the integrity of the data and the accuracy of the data analysis.

\section{Competing interests None declared.}

Patient and public involvement Patients and/or the public were not involved in the design, or conduct, or reporting, or dissemination plans of this research.

\section{Patient consent for publication Not required.}

Ethics approval This study did not require ethical approval since data were extracted from the administrative databases of the Regional Repository of MicroData using an anonymous identifier.

Provenance and peer review Not commissioned; externally peer reviewed.

Data availability statement No data are available. All data relevant to the study are included in the article or uploaded as online supplementary information.

Open access This is an open access article distributed in accordance with the Creative Commons Attribution Non Commercial (CC BY-NC 4.0) license, which permits others to distribute, remix, adapt, build upon this work non-commercially, and license their derivative works on different terms, provided the original work is properly cited, appropriate credit is given, any changes made indicated, and the use is non-commercial. See: http://creativecommons.org/licenses/by-nc/4.0/.

\section{ORCID iD}

Luigi Castriotta http://orcid.org/0000-0001-8775-2640 


\section{REFERENCES}

1 Eurostat statistics explained. Available: https://ec.europa.eu/ eurostat/statistics-explained/index.php/Glossary:Material_ deprivation

2 European Commission. Employment, Social Affairs \& Inclusion: Social protection \& social inclusion. Available: https://ec.europa.eu/ social/main.jsp?langld=en\&catld $=750$

3 OECD social, employment and migration working papers. Measures of material deprivation in OECD countries. Available: https:// www.oecd-ilibrary.org/docserver/866767270205.pdf?expires= $1589458562 \& i d=i d \& a c c n a m e=$ guest\&checksum $=5$ CDF00E1BB7C 159B204BD4B268715E17

4 Townsend P. Poverty in the United Kingdom. London: Allen Lane and Penguin Books, 1979. https://www.poverty.ac.uk/free-resourcesbooks/poverty-united-kingdom

5 Sen A. Poor, relatively speaking *. Oxf Econ Pap 1983;35:153-69.

6 Callan T, Nolan B, Whelan CT. Resources, deprivation and the measurement of poverty. J Soc Policy 1993;22:141-72.

7 Nolan B, Whelan CT. Resources, deprivation and poverty. Oxford: Oxford University Press, 1996.

8 Kangas O, Ritakallio VM. Different methods- different results? Approaches to multidimensional poverty. In: Andre ्̃̈̈ H-J, ed. Empirical poverty research in a comparative perspective. Aldershot: Ashgate, 1998: 167-203.

9 Lyte R, Maitre B, Nolan B, et al. Persistent and consistent poverty in the 1994 and 1995 waves of the European community household panel survey. Rev Income Wealth 2001;47:427-49.

10 Whelan CT, Layte R, Matre B. Persistent deprivation in European Union. Institute for Social and Economic Research, 2001.

11 Perry $B$. The mismatch between income measures and direct outcome measures of poverty. Soc Policy J N Z 2002;19:101-27.

12 Bradshaw J, Finch N. Overlaps in dimensions of poverty. J Soc Policy 2003;32:513-25.

13 Tøge AG, Bell R. Material deprivation and health: a longitudinal study. BMC Public Health 2016;16:747.

14 Benach J, Yasui Y, Borrell C, et al. Material deprivation and leading causes of death by gender: evidence from a nationwide small area study. J Epidemiol Community Health 2001;55:239-45.

15 Benach J, Yasui Y, Borrell C, et al. The public health burden of material deprivation: excess mortality in leading causes of death in Spain. Prev Med 2003;36:300-8.

16 Coster JE, Turner JK, Bradbury D, et al. Why do people choose emergency and urgent care services? A rapid review utilizing a systematic literature search and narrative synthesis. Acad Emerg Med 2017;24:1137-49.

17 Lowthian JA, Curtis AJ, Jolley DJ, et al. Demand at the emergency department front door: 10-year trends in presentations. Med J Aust 2012;196:128-32.

18 Drummond AJ. No room at the inn: overcrowding in Ontario's emergency departments. CJEM 2002;4:91-7.

19 Australian Institute of Health and Welfare. Australian hospital statistics 2009-10: emergency department care and elective surgery waiting times. Canberra: AHIW, 2010. https://www.aihw.gov.au/ getmedia/1b305ffc-b7a4-4f80-aa66-d90614c5f8f4/12271.pdf.aspx? inline $=$ true

20 Nicholl J, Mason S. Return of the "corridors of shame"? BMJ 2013;347:f4343.

21 Huntley A, Lasserson D, Wye L, et al. Which features of primary care affect unscheduled secondary care use? A systematic review. BMJ Open 2014;4:e004746.

22 Brokamp C, Beck AF, Goyal NK, et al. Material community deprivation and hospital utilization during the first year of life: an urban population-based cohort study. Ann Epidemiol 2019;30:37-43.

23 Raphael D. Social determinants of health: Canadian perspectives. 2nd edn. Toronto, ON: Canadian Scholars ${ }^{\mathrm{TM}}$ Press Inc, 2009.

24 Braveman P, Gottlieb L. The social determinants of health: it's time to consider the causes of the causes. Public Health Rep 2014;129(Suppl 2):19-31.
25 Committee on Integrating Primary Care and Public Health, Board on Population Health and Public Health Practice, Institute of Medicine. Primary care and public health: exploring integration to improve population health. Washington: National Academies Press, 2012.

26 Gruen RL, Pearson SD, Brennan TA. Physician-citizens--public roles and professional obligations. JAMA 2004;291:94-8.

27 Gallio G, Cogliati Dezza MG. "La citt che cura. Microaree e periferie della salute" Edizioni Alpha Beta Verlag. Merano, 2018.

28 Foot J. La Repubblica dei matti. Franco Basaglia E La psichiatria radicale in Italia, 1961-1978. Milano, Feltrinelli, 2014. http://journals. openedition.org/diacronie/4210

29 Panizon F. Cari genitori, cari nonni, cari insegnanti, cari pediatri. di Editore: Medico e Bambino, 2014. ISBN: 8890795298.

30 National Institute of Statistics. Demography in figures. Available: http://demo.istat.it/

31 II programma habitat Microaree Trieste. Linee di indirizzo progettuali E operative. Available: https://www.disuguaglianzedisalute.it/ wp-content/uploads/2019/10/01allegato-2018_ASUITS_Linee-diindirizzo-HM.pdf

32 Rosenbaum PR, Rubin DB. The central role of the propensity score in observational studies for causal effects. Biometrika 1983a;70:41-55.

33 Austin PC. An introduction to propensity score methods for reducing the effects of confounding in observational studies. Multivariate Behav Res 2011;46:399-424.

34 Rosenbaum PR. Observational studies. 2nd edn. New York, NY: Springer-Verlag, 2002. ISBN: 978-1-4757-3692-2.

35 Rosenbaum PR, Rubin DB. Constructing a control group using multivariate matched sampling methods that incorporate the propensity score. Am Statistic 1985;39:33-8.

36 Parsons LS. Reducing bias in a propensity score matched-pair sample using greedy matching techniques. Proceedings of the Twenty-Six Annual SASÂ® Users Group International Conference, Cary, NC: SAS Institute Inc, 2000:214-26.

37 Caranci N, Biggeri A, Grisotto L, et al. The Italian deprivation index at census block level: definition, description and association with general mortality]. Epidemiol Prev 2010;34:167-76.

38 Charlson ME, Pompei P, Ales KL, et al. A new method of classifying prognostic comorbidity in longitudinal studies: development and validation. J Chronic Dis 1987;40:373-83.

39 Anatomical therapeutic chemical classification system. Available: https://www.whocc.no/atc_ddd_index/

40 Kripalani S, Theobald CN, Anctil B, et al. Reducing Hospital readmission rates: current strategies and future directions. Annu Rev Med 2014;65:471-85.

41 Panagioti M, Richardson G, Small N, et al. Self-management support interventions to reduce health care utilisation without compromising outcomes: a systematic review and meta-analysis. BMC Health Serv Res 2014;14:356.

42 Groffen DAl, Bosma H, van den Akker M, et al. Material deprivation and health-related dysfunction in older Dutch people: findings from the SMILE study. Eur J Public Health 2008;18:258-63.

43 Randall JR, Vokey S, Loewen $\mathrm{H}$, et al. A systematic review of the effect of early interventions for psychosis on the usage of inpatient services. Schizophr Bull 2015;41:1379-86.

44 McFarlane WR, Susser E, McCleary R, et al. Reduction in incidence of hospitalizations for psychotic episodes through early identification and intervention. Psychiatr Serv 2014;65:1194-200.

45 Krumholz HM, Bernheim SM. Considering the role of socioeconomic status in hospital outcomes measures. Ann Intern Med 2014;161:833-4.

46 Naylor MD, Brooten D, Campbell R, et al. Comprehensive discharge planning and home follow-up of hospitalized elders: a randomized clinical trial. JAMA 1999;281:613-20.

47 Joynt Maddox KE, Reidhead M, Hu J, et al. Adjusting for social risk factors impacts performance and penalties in the hospital readmissions reduction program. Health Serv Res 2019;54:327-36.

48 Kangovi S, Barg FK, Carter T, et al. Understanding why patients of low socioeconomic status prefer hospitals over ambulatory care. Health Aff 2013;32:1196-203. 